\title{
CARACTERIZAÇÃO MORFOLÓGICA DE VARIEDADES DE MANDIOCA (MANIHOT ESCULENTA CRANTZ) NO EXTREMO SUL DA BAHIA.
}

\author{
AUTOR: PAULO VITOR ALMEIDA NASCIMENTO \\ CO-AUTOR/ORIENTADOR: LIVIA SANTOS LIMA LEMOS
}

Resumo: A mandioca (Manihot esculenta Crantz) é uma planta com alta capacidade adaptativa, em que tanto a raiz quanto a parte aérea são objeto de interesse para a alimentação humana e/ou animal. $\mathrm{Na}$ região do Extremo Sul da Bahia verifica-se falta de diversidade genética da mandioca, visto que a maioria dos agricultores opta por cultivar, em suas lavouras, apenas a variedade Caravela. O objetivo desse trabalho foi caracterizar morfologicamente as variedades do banco de germoplasma do Maniveiro Guardião, a fim identificar qual variedade melhor se adaptou à região. A análise estatística foi realizada por meio da avaliação qualitativa das características morfológicas, através de variáveis multicategóricas. Os resultados obtidos mostraram diversidade fenotípica, tanto na raiz quanto na parte aérea da planta. Observaram-se, em um mesmo descritor, caracteres diferentes, evidenciando uma não confiabilidade deste descritor na caracterização, ao passo que, em outros, as análises estatísticas permitiram verificar homogeneidade nas observações, possibilitando o estabelecimento de características.

Palavras-chave: Raiz de Mandioca, Descritores Morfológicos, Extremo Sul da Bahia. 